\title{
ONE CRITERION FOR UNIVALENCY
}

\author{
MAMORU NUNOKAWA, MILUTIN OBRADOVIĆ AND SHIGEYOSHI OWA
}

(Communicated by Paul S. Muhly)

ABSTRACT. In this note we give one criterion for the functions $f(z)=z+$ $a_{2} z^{2}+\cdots$ to be univalent in $|z|<1$.

Let $f(z)$ and $g(z)$ be analytic in the unit disc $U=\{z:|z|<1\}$. We say that the function $f(z)$ is subordinate to $g(z)$, written $f(z) \prec g(z)$, if $g(z)$ is univalent in $U, f(0)=g(0)$ and $f(U) \subset g(U)$.

We can easily derive the following lemma from one earlier result by Miller and Mocanu ([1, Theorem 3, p. 190]). We can find more about differential subordinations in the same paper.

Lemma 1. If $p(z)=1+p_{1} z+\cdots$ is analytic in $U$ and

$$
z p^{\prime}(z) \prec z,
$$

then

$$
p(z) \prec 1+z
$$

and the function $1+z$ is the best dominant for the differential subordination (1).

We owe the next lemma to Ozaki and Nunokawa [2].

Lemma 2. Let the function $f(z)$ given by

$$
f(z)=z+\sum_{n=2}^{\infty} a_{n} z^{n}
$$

be analytic in $U$ and

$$
\operatorname{Re}\left\{\frac{f(z)^{2}}{z^{2} f^{\prime}(z)}\right\} \geq \frac{1}{2} \quad(z \in U),
$$

(which is equivalent to $\left|z^{2} f^{\prime}(z) / f(z)^{2}-1\right| \leq 1 \quad(z \in U)$; then $f(z)$ is univalent in $U$.

By using these lemmas we obtain

Received by the editors November 16, 1988.

1980 Mathematics Subject Classification (1985 Revision). Primary 30C45. 
Theorem. Let the function $f(z)$ given by

$$
f(z)=z+\sum_{n=2}^{\infty} a_{n} z^{n}
$$

be analytic in $U$ with $f(z) / z \neq 0,0<|z|<1$, and

$$
\left|\left(\frac{z}{f(z)}\right)^{\prime \prime}\right| \leq 1 \quad(z \in U)
$$

then $f(z)$ is univalent in $U$.

Proof. If we put

$$
p(z)=\frac{z}{f(z)}-z\left(\frac{z}{f(z)}\right)^{\prime}
$$

then we get

$$
p^{\prime}(z)=-z\left(\frac{z}{f(z)}\right)^{\prime \prime}
$$

and

$$
p(z)=\frac{z^{2} f^{\prime}(z)}{f(z)^{2}} .
$$

For such $p(z)$ from Lemma 1 we have that the following implication

$$
-z^{2}\left(\frac{z}{f(z)}\right)^{\prime \prime} \prec z \Rightarrow \frac{z^{2} f^{\prime}(z)}{f(z)^{2}} \prec 1+z
$$

is true and the function $1+z$ is the best dominant.

On the other hand from (2) we obtain

$$
\left|z^{2}\left(\frac{z}{f(z)}\right)^{\prime \prime}\right| \leq|z|^{2}<1 \quad(z \in U),
$$

which implies

$$
z^{2}\left(\frac{z}{f(z)}\right)^{\prime \prime} \prec z
$$

and so

$$
-z^{2}\left(\frac{z}{f(z)}\right)^{\prime \prime} \prec z
$$

Therefore, from (3) we have

$$
\frac{z^{2} f^{\prime}(z)}{f(z)^{2}} \prec 1+z
$$

or

$$
\left|\frac{z^{2} f^{\prime}(z)}{f(z)^{2}}-1\right|<1 .
$$

Finally, from Lemma 2 we conclude that $f(z)$ is univalent in $U$. 


\section{ACKNOWLEDGMENT}

This paper was completed at the Department of Mathematics, Gumma University, Gumma, Japan while the second author was visiting from Department of Mathematics, Faculty of Technology and Metallurgy, University of Belgrade, Belgrade, Yugoslavia.

\section{REFERENCES}

1. S. S. Miller and P. T. Mocanu, On some classes of first-order differential subordinations, Michigan Math. J. 32 (1985), 185-195.

2. S. Ozaki and M. Nunokawa, The Schwarzian derivative and univalent functions, Proc. Amer. Math. Soc. 33 (1972), 392-394.

Department of Mathematics, Gumma University, Maebashi, Gumma 371, Japan

Department of Mathematics, Faculty of Technology and Metallurgy, University of Belgrade, 4 Karnegieva Street, 1100 Belgrade, Yugoslavia

Department of Mathematics, Kinki University, Higashi-Osaka, Osaka 577, Japan 